\title{
Causes and prevalence of inadequate pulmonary function testing among patients with systemic sclerosis
}

\author{
Pichaporn Sumphao-Ngern ${ }^{1}$, Chingching Foocharoen ${ }^{1}$, Watchara Boonsawat ${ }^{1}$, \\ Ajanee Mahakkanukrauh ${ }^{1}$, Siraphop Suwannaroj ${ }^{1}$, Uraiwan Sae-Oue ${ }^{2}$, Sittichai Netwijitpann ${ }^{1}$, \\ Ratanavadee Nanagara ${ }^{1}$; Scleroderma Research Group
}

'Department of Medicine, Faculty of Medicine, Khon Kaen University, Khon Kaen, Thailand

${ }^{2}$ Pulmonary Investigation Unit, Faculty of Medicine, Khon Kaen University, Khon Kaen, Thailand

Submitted: 6 May 2014

Accepted: 7 June 2014

Arch Med Sci 2015; 11, 6: 1255-1260

DOI: $10.5114 /$ aoms.2015.56352

Copyright $\odot 2015$ Termedia \& Banach

\section{Abstract}

Introduction: Spirometry is a screening tool for evaluating the degree of restrictive lung disease in systemic sclerosis (SSc). Observations indicated that some patients could not complete the test. The aim of the study was to identify the prevalence, causes and clinical predictors of an inadequate pulmonary function test (PFT) in SSc.

Material and methods: A cross-sectional study was performed among SSC patients over 18 years old followed up at Srinagarind Hospital, Khon Kaen, Thailand, during January 2006-December 2012. The adequacy of the PFT was based on the acceptable blow criteria as set out by the American Thoracic Society and the European Respiratory Society 2005 Standardizations of Spirometry.

Results: Two hundred and forty-nine patients were included (female to male ratio was $2: 1$ ). The mean age at performing PFT was $51.4 \pm 11.1$ years (range: 19.6-79.5). Median duration of disease at performing PFT was 2 years (IQR: 0.6-4.4). Inadequate PFT occurred in 73 cases (prevalence $29.3 \%$ : $95 \% \mathrm{Cl}: 23.6-35.0$ ); the majority (60 cases; $82.2 \%$ ) had an expiration time $<6 \mathrm{~s}$ and the others were due to plateau $<1 \mathrm{~s}$ (11 cases; 15\%), air leak around mouth piece (1 case; $1.4 \%$ ) and hesitation (1 case; $1.4 \%$ ). Thirteen of $73(17.8 \%)$ had an unusable graph with the overall prevalence of $5.2 \%$ (95\% Cl: 2.4-8.0). The factor associated with inadequate PFT was docy mass index $(\mathrm{BMI})<18.5 \mathrm{~kg} / \mathrm{m}^{2}(\mathrm{OR}=2.17: 95 \% \mathrm{Cl}: 1.49-3.17)$; the same factor was associated with an unusable graph, which was confirmed by the multivariate analysis ( $\mathrm{OR}=5.21 ; 95 \% \mathrm{Cl}: 1.60-16.95)$.

Conclusions: One-third of Thai SSc patients had an inadequate pulmonary function test - the majority because of inadequate time for expiring. Low BMI influenced the effectiveness of the test, leading to an incomplete graph for evaluating lung disease in SSc.

Key words: systemic sclerosis, scleroderma, pulmonary function test, forced vital capacity.

\section{Introduction}

Systemic sclerosis (SSc) is a rare disease for which skin tightness is the hallmark. The extent of skin tightness is classified into 2 major subsets (a) limited cutaneous systemic sclerosis (IcSSc) and (b) diffuse

\author{
Corresponding author: \\ Dr. Chingching Foocharoen \\ Division of Allergy- \\ Immunology-Rheumatology \\ Department of Medicine \\ Faculty of Medicine \\ Khon Kaen University \\ Khon Kaen, 40002 Thailand \\ Phone: 66-43-363-746, \\ 66-43-363-664 \\ E-mail: fching@kku.ac.th
}


cutaneous systemic sclerosis (dcSSc) [1]. Skin tightness in IcSSc is limited to the face, hands, feet, forearms and legs, whereas in dcSSc the skin tightness includes the trunk and both extremities. Fibrosis is a predominant pathological finding in SSc which presents in the skin and the internal organs including the kidney, lung, heart and intestines [2-6]. However, the fibrosis could be revealed in a non-life threatening organ such as ocular or thyroid, and the clinical manifestations might be unrecognized [7, 8]. Infection, genetic, and environmental factors are reported to be involved in initiation of the disease, however; the exact pathogenesis of the disease is complex and not clear $[9,10]$.

Interstitial lung fibrosis in SSc is not uncommon, and the severity of pulmonary involvement indicates the prognosis [11]. Interstitial lung fibrosis and pulmonary vascular disease are thus the major causes of mortality [12-14]. Serum tumor necrosis factor $\alpha$ (TNF- $\alpha)$ is elevated in SSc patients, and the rise supports the development of interstitial lung fibrosis and pulmonary arterial hypertension (PAH) [15]. However, the role of anti-TNF- $\alpha$ in SSc with interstitial lung fibrosis and $\mathrm{PAH}$ is unknown. Pulmonary function tests - especially spirometry - are routinely used as an initial evaluation for assessing the severity of pulmonary involvement and also at subsequent follow-up [14]. Forced vital capacity (FVC) $<80 \%$ represents the restrictive lung disease, which is the most common pulmonary function test finding for SSc [16]. Although spirometry is a good screening tool for early restrictive lung disease detection in SSc, there are some technical limitations according to our observation of SSC patients in clinical practice (narrow mouth opening, muscle weakness and severe skin tightness); consequently, some patients cannot perform the spirometry test and some therefore have an inadequate pulmonary function test.

We wanted to investigate the prevalence, the causes and the clinical predictors of inadequate pulmonary function test among SSc patients. If the causes of inadequate pulmonary function tests could be identified, we might be able to predict which SSc patients would most likely have an inadequate pulmonary function test; thereby guiding us to choose an alternative test for evaluating pulmonary involvement progression. The results of this research could assist physicians by decreasing the time and money spent on an unproductive test.

\section{Material and methods}

We conducted a cross-sectional study of SSC patients over 18 years of age, attending the Scleroderma Clinic at Srinagarind Hospital, Khon Kaen University, Khon Kaen, Thailand, between
January 2006 and December 2012. We excluded patients with any other connective tissue disease.

\section{Operational definitions}

A diagnosis of SSc was based on the American College of Rheumatology criteria [17]. Systemic sclerosis was classified as the limited or diffuse type as per the classification by LeRoy et al. [18]. Date of onset was the date when the patient had the first symptoms of SSc. Myositis was diagnosed if the muscle enzyme creatine phosphokinase was elevated or an abnormal finding was found on the electromyography. Muscle weakness was defined when the patients had muscle weakness mainly in the shoulder and hip girdles that related to SSc [19]. The skin score was evaluated using the modified Rodnan's skin score (mRSS) method. Restrictive lung disease was classified as (a) mild restrictive lung - FVC between $60 \%$ and $79 \%$ predicted (b) moderate restrictive lung - FVC between $40 \%$ and $59 \%$ predicted and (c) severe restrictive lung - FVC $<40 \%$ predicted. The last visit for doing the pulmonary function test was included in our analysis.

The adequacy of the pulmonary function test was based on acceptable blow criteria ATS/ERS 2005 Standardizations of Spirometry [20]: 1) without an unsatisfactory start of expiration, characterized by excessive hesitation or a false start, an extrapolated volume (EV) $>5 \%$ of FVC or 0.150 l, whichever is greater; 2) without coughing during the first second of the maneuver, thereby affecting the measured force of the expiratory volume within $1 \mathrm{~s}\left(\mathrm{FEV}_{1}\right)$, or any other cough that - in the technician's judgment - interfered with the measurement of accurate results; and, 3) without early termination of expiration.

The latter was defined as: (1) the subject could not or should not continue further exhalation; (2) the volume - time curve indicated no change in volume (<0.025 l) for $\geq 1 \mathrm{~s}$; (3) the subject had tried to exhale for $\geq 3 \mathrm{~s}$ in children under 10 years of age and for $\geq 6 \mathrm{~s}$ in subjects over 10 years of age; (4) without a Valsalva maneuver (glottis closure) or hesitation during the maneuver that causes a cessation of airflow, which precludes accurate measurement of FEV ${ }_{1}$ or FVC; (5) without a leak; (6) without an obstructed mouthpiece (e.g., obstruction due to the tongue being placed in front of the mouthpiece, or teeth in front of the mouthpiece, or mouthpiece deformation due to biting); and/or (7) without evidence of an extra breath being taken during the maneuver.

A usable graph need only meet conditions 1 and 2 above, while an acceptable graph must meet all of the above seven conditions [20]. An adequate pulmonary function test was indicated when the expired time was $\geq 6 \mathrm{~s}$ and the volume - time graph 
showed no change in volume (plateau) $\geq 1 \mathrm{~s}$. An inadequate pulmonary function test could be subdivided into a usable volume-time graph (plateau time $\geq 1 \mathrm{~s}$ ) and an unusable volume-time graph (if the graph did not meet any of the above criteria).

The primary outcome of this study was finding the cause(s) of an inadequate pulmonary function test while the secondary outcome was finding the prevalence of an inadequate pulmonary function test at the Scleroderma Clinic and/or the clinical predictors of an inadequate pulmonary function test.

\section{Statistical analysis}

The clinical characteristics were categorized according to the theory being studied. All of the data were classified into dichotomous or polytomous variables or continuous variables. The codes were set for every categorical variable. The differences in clinical characteristics between an adequate and an inadequate pulmonary function test were investigated. The categorical data were tested for significance using the $\chi^{2}$ or Fisher's exact test. The continuous data were analyzed using the Student $t$-test or the Wilcoxon rank sum, as appropriate. The prevalence of an inadequate pulmonary function test was stated together with the respective $95 \%$ confidence interval $(\mathrm{Cl})$. The odds ratio with the respective $95 \% \mathrm{Cl}$ and $p$-value were used to determine which clinical characteristics are significantly associated with an inadequate pulmonary function test. The variables with a $p$-value $<0.10$ were entered into a multiple logistic regression model then the backward elimination method was applied for model fitting. Variables were then re-tested for significance using the Wald $\chi^{2}$ statistic. All statistical tests were two-tailed and a $p$-value of $<0.05$ was considered statistically significant. All data analyses were performed by using STATA version 11.2 (StataCorp., College Station, TX, USA).

The study was designed by the authors and approved by the Human Research Ethics Committee of Khon Kaen University (HE551422). The sponsors had no role in this study.

\section{Results}

In total 401 medical records were reviewed. Ninety-two patients were excluded because of SSc overlap with other connective tissue disease and 60 were excluded because of PFT not being performed; therefore a total of 249 medical records were included in this study (164 females vs. 85 males). The respective mean age of onset of the disease and age at time of the pulmonary function test were $47.9 \pm 11.9$ years (range: $11.3-75.6$ ) and $51.4 \pm 11.1$ years (range: $19.6-79.4$ ). The majority ( 222 cases; $89.5 \%$ ) had the diffuse cutaneous systemic sclerosis subset. The median duration of the disease at the time of the PFT was 2.0 years (IQR: 0.6-4.4). The mean BMI at the time of the test was $21.7 \pm 3.4 \mathrm{~kg} / \mathrm{m}^{2}$ (range: $12.8-40.3$ ).

Seventy-three cases had an inadequate pulmonary function test. The prevalence of an inadequate pulmonary function test was $29.3 \%(95 \% \mathrm{Cl}$ : 23.6-35.0), of which 60 cases (82.2\%) were due to an expiration under $6 \mathrm{~s}$; however, the graphs were interpretable. The remainder were uninterpretable as: (a) the plateau on the volume - time graph was < 1 s (11 cases; 15.1\%); (b) there was an air leak around the mouth piece (1 case; $1.4 \%$ ) and/or, hesitation (1 case; $1.4 \%$ ) (Figure 1). The prevalence of an unusable volume-time graph for interpretation was $5.2 \%(95 \% \mathrm{Cl}: 2.4-8.0)$. The mean FVC of the patients with a usable graph was $69.2 \pm 14.7 \%$ predicted (range: $20-105$ ). Half (126; $52.7 \%$ ) had mild restrictive lung disease while one-fifth had a normal pulmonary function test

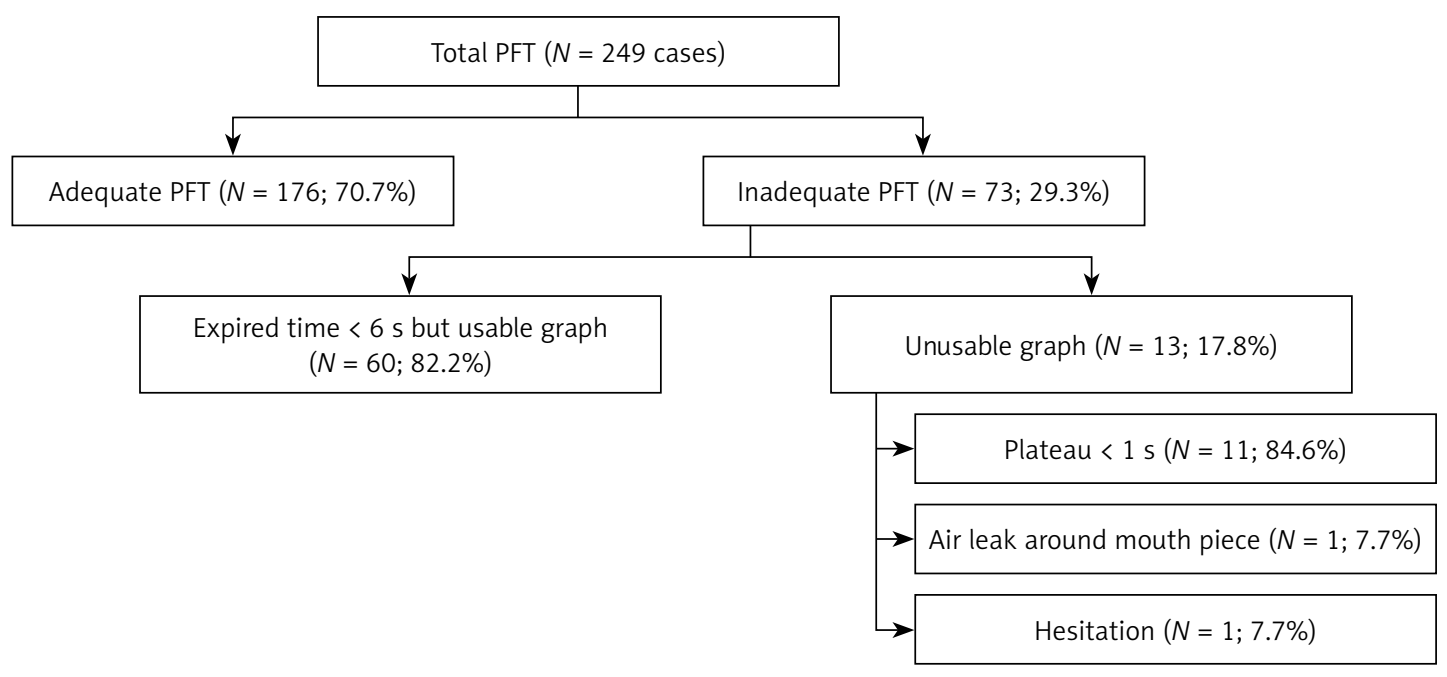

Figure 1. Characteristics of pulmonary function test (PFT) 
P. Sumphao-Ngern, C. Foocharoen, W. Boonsawat, A. Mahakkanukrauh, S. Suwannaroj, U. Sae-Oue, S. Netwijitpan, R. Nanagara; Scleroderma Research Group

(54; $22.6 \%)$ and another one-fifth had a moderately restrictive lung $(52 ; 21.8 \%)$.

The clinical differences between the patients who had an adequate vs. an inadequate pulmonary function test are presented in Table I. Body mass index (BMI) was the only clinical parameter that affected the effectiveness of the pulmonary function test: a BMI $<18.5 \mathrm{~kg} / \mathrm{m}^{2}$, which was associated with an inadequate pulmonary function test $(\mathrm{OR}=2.02: 95 \% \mathrm{Cl}: 1.39-2.93)$. Other factors were not related to the outcome of interest (i.e. age, facial and severity of truncal skin tightness, muscle strength and cardiac function) (Table I).

The clinical differences between the patients who had a usable and an unusable graph for interpretation are presented in Table II. Body mass index $<18.5 \mathrm{~kg} / \mathrm{m}^{2}$ and muscle weakness were as- sociated with inadequate pulmonary function test performance with OR of 2.02 (95\% Cl: 1.39-2.93) by univariate analysis. After multivariate analysis, only $\mathrm{BMI}<18.5 \mathrm{~kg} / \mathrm{m}^{2}$ was a clinical parameter associated with unusable graph for interpretation with OR of 5.2 (95\% Cl: 1.60--16.95) (Table II). Most patients had no serious complication during or after performing the pulmonary function test. Twenty-two cases (8.8\%) revealed hypoxemia and $2(0.8 \%)$ had rising blood pressure after performing the pulmonary function test.

\section{Discussion}

The pulmonary function test is a noninvasive screening tool for evaluating pulmonary disease, particularly for chronic lung disease including pulmonary fibrosis in SSc patients. A restrictive lung

Table I. Clinical differences between the patients with an adequate vs. an inadequate pulmonary function test

\begin{tabular}{|lccc|}
\hline Clinical parameters & $\begin{array}{c}\text { Adequate PFT } \\
\boldsymbol{N}=176\end{array}$ & $\begin{array}{c}\text { Inadequate PFT } \\
\boldsymbol{N}=73\end{array}$ & OR (95\% CI) \\
\hline Female & $65.9 \%$ & $65.8 \%$ & $1.00(0.66-1.49)$ \\
\hline dcSSc subset & $90.3 \%$ & $87.7 \%$ & $0.83(0.47-1.47)$ \\
\hline Age $>65$ years & $11.4 \%$ & $9.6 \%$ & $0.87(0.44-1.69)$ \\
\hline BMI $<18.5 \mathrm{~kg} / \mathrm{m}^{2}$ & $9.8 \%$ & $27.8 \%$ & $2.17(1.49-3.17)^{\star}$ \\
\hline Total mRSS $>20$ points & $15.0 \%$ & $12.5 \%$ & $0.86(0.47-1.56)$ \\
\hline mRSS face and trunk $\geq 6$ & $0.6 \%$ & $1.4 \%$ & $1.72(0.4-6.97)$ \\
\hline EF $<50 \%$ & $5.4 \%$ & $4.4 \%$ & $0.86(0.3-2.34)$ \\
\hline RVSP $>40$ mm Hg & $17.1 \%$ & $21.8 \%$ & $1.22(0.73-2.04)$ \\
\hline Myositis & $23.4 \%$ & $22.9 \%$ & $0.98(0.61-1.57)$ \\
\hline Muscle weakness & $6.9 \%$ & $11.3 \%$ & $1.42(0.80-2.53)$ \\
\hline
\end{tabular}

PFT - Pulmonary function test, OR - odds ratio, CI - confidence interval, dcSSc - diffuse cutaneous systemic sclerosis, BMI - body mass index, mRSS - modified Rodnan skin score, EF-ejection fraction, RVSP - right ventricular systolic pressure; *statistically significant.

Table II. Clinical differences between the patients who had a usable graph and an unusable graph for interpretation

\begin{tabular}{|c|c|c|c|c|}
\hline Clinical parameters & $\begin{array}{l}\text { Usable graph } \\
\qquad N=236\end{array}$ & $\begin{array}{l}\text { Unusable graph } \\
\qquad N=13\end{array}$ & $\begin{array}{l}\text { Crude OR } \\
(95 \% \mathrm{Cl})\end{array}$ & $\begin{array}{l}\text { Adjusted OR } \\
(95 \% \mathrm{Cl})\end{array}$ \\
\hline Female & $64.8 \%$ & $84.6 \%$ & $2.85(0.65-12.57)$ & - \\
\hline dcSSc subset & $90.6 \%$ & $70.0 \%$ & $0.26(0.09-1.80)$ & - \\
\hline Age $>65$ years & $11.1 \%$ & $7.7 \%$ & $0.68(0.09-5.04)$ & - \\
\hline $\mathrm{BMI}<18.5 \mathrm{~kg} / \mathrm{m}^{2}$ & $13.3 \%$ & $46.2 \%$ & $4.84(1.72-13.60)^{\star}$ & $5.21(1.60-16.95)^{*}$ \\
\hline Total mRSS > 20 points & $13.4 \%$ & $30.8 \%$ & $2.67(0.87-8.19)$ & $2.26(0.61-8.36)$ \\
\hline mRSS face and trunk $\geq 6$ & $0.9 \%$ & $0 \%$ & NA & - \\
\hline$E F<50 \%$ & $5.3 \%$ & $0 \%$ & NA & - \\
\hline RVSP > $40 \mathrm{~mm} \mathrm{Hg}$ & $17.7 \%$ & $37.5 \%$ & $2.63(0.66-10.42)$ & - \\
\hline Myositis & $23.7 \%$ & $15.4 \%$ & $0.60(0.14-2.63)$ & - \\
\hline Muscle weakness & $7.4 \%$ & $23.1 \%$ & $3.36(1.0-11.23)^{*}$ & $2.86(0.65-12.49)$ \\
\hline
\end{tabular}

$O R$ - Odds ratio, Cl - confidence interval, dcSSc - diffuse cutaneous systemic sclerosis, BMI - body mass index, mRSS - modified Rodnan skin score, EF-ejection fraction, RVSP - right ventricular systolic pressure; *statistically significant. 
pattern is commonly detected in SSc patients; however, a complete performance of the test depends on several factors (e.g., patient coordination, mouth closed ensuring no leaks).

In SSc, some factors that could lead to an inadequate or incomplete pulmonary function test such as tightness of the skin on the face might cause air leaks during performance of the pulmonary function test. According to our observations, the prevalence of an inadequate pulmonary function test was high but fortunately most of the patients had a usable graph for interpretation. An inadequate extension of the expiration time to $6 \mathrm{~s}$ and a BMI under $18.5 \mathrm{~kg} / \mathrm{m}^{2}$ (or malnutrition status) were the only factors associated with both an inadequate pulmonary function test and an unusable graph for interpretation of SSc. According to the results from a previous study, malnutrition and body composition could affect the results of a pulmonary function test, particularly FVC [21, 22], so this might explain why malnutrition was a clinical parameter predictive of an inadequate pulmonary function test in SSc. We therefore suggest carefully considering PFT interpretation among SSc patients with a BMI under $18.5 \mathrm{~kg} / \mathrm{m}^{2}$ and using the alternative screening tool for evaluating the severity of restrictive lung disease in those patients if PFT is inadequate.

According to our results, muscle weakness was not significantly associated with an inadequate pulmonary function test or an unusable graph for interpretation. In general, muscle weakness in SSc almost always presents on the proximal part [23] not in the respiratory muscles as in polymyositis or dermatomyositis, which directly affect the results of the pulmonary function test [24]. To avoid any confounding of our analysis, we excluded overlap SSc-polymyositis from our study, so it was not surprising that muscle weakness did not influence the pulmonary function test in our SSc patients.

This study had some limitations due to its retrospective nature and the relatively small number of patients. Notwithstanding, our study is the first report on the clinical parameters associated with an inadequate pulmonary function test leading to an unusable graph among SSc patients. These are, therefore, important preliminary data showing the limitations of a pulmonary function test among SSc patients.

In conclusion, around one-third of the Thai SSC patients in our study had an inadequate pulmonary function test. In the majority of cases, it was related to an inadequate time for expiration. One in twenty had an unusable graph from the pulmonary function test. A low BMI (malnourished status) influenced the effectiveness of the pulmonary function test and led to an incomplete graph, making evaluating the lung disease in SSc impracticable.

\section{Acknowledgments}

The authors thank the Faculty of Medicine and the Scleroderma Research Group, Khon Kaen University for the support and Mr. Bryan Roderick Hamman and Mrs. Janice Loewen-Hamman for assistance with the English language presentation.

\section{Conflict of interest}

The authors declare no conflict interest.

\section{References}

1. Silver RM. Clinical aspects of systemic sclerosis (scleroderma). Ann Rheum Dis 1991; 50 Suppl. 4: 854-61.

2. Steen VD, Medsger TA Jr. Severe organ involvement in systemic sclerosis with diffuse scleroderma. Arthritis Rheum 2000; 43: 2437-44.

3. Steen V. The heart in systemic sclerosis. Curr Rheumatol Rep 2004; 6: 137-40.

4. Bussone G, Mouthon L. Interstitial lung disease in systemic sclerosis. Autoimmun Rev 2011; 10: 248-55.

5. Cohen S. The gastrointestinal manifestations of scleroderma: pathogenesis and management. Gastroenterology 1980; 79: 155-66.

6. Denton CP, Lapadula G, Mouthon L, Müller-Ladner U. Renal complications and scleroderma renal crisis. Rheumatol Oxf Engl 2009; 48 Suppl. 3: iii32-5.

7. Waszczykowska A, Goś R, Waszczykowska E, Dziankowska-Bartkowiak B, Jurowski P. Prevalence of ocular manifestations in systemic sclerosis patients. Arch Med Sci 2013; 9: 1107-13.

8. Shah AA, Wigley FM. Often forgotten manifestations of systemic sclerosis. Rheum Dis Clin North Am 2008; 34: 221-38.

9. Kowalczyk MJ, Dańczak-Pazdrowska A, Szramka-Pawlak B, Zaba R, Silny W, Osmola-Mańkowska A. Expression of selected human endogenous retroviral sequences in skin and peripheral blood mononuclear cells in morphea. Arch Med Sci 2012; 8: 819-25.

10. Geyer M, Müller-Ladner U. The pathogenesis of systemic sclerosis revisited. Clin Rev Allergy Immunol 2011; 40: 92-103.

11. Diot E, Boissinot E, Asquier E, et al. Relationship between abnormalities on high-resolution $\mathrm{CT}$ and pulmonary function in systemic sclerosis. Chest 1998; 114: 1623-9.

12. Foocharoen C, Nanagara R, Kiatchoosakun S, Suwannaroj S, Mahakkanukrauh A. Prognostic factors of mortality and 2-year survival analysis of systemic sclerosis with pulmonary arterial hypertension in Thailand. Int J Rheum Dis 2011; 14: 282-9.

13. Tyndall AJ, Bannert B, Vonk M, et al. Causes and risk factors for death in systemic sclerosis: a study from the EULAR Scleroderma Trials and Research (EUSTAR) database. Ann Rheum Dis 2010; 69: 1809-15.

14. Lopes AJ, Capone D, Mogami R, Menezes SLS de, Guimarães FS, Levy RA. Systemic sclerosis-associated interstitial pneumonia: evaluation of pulmonary function over a five-year period. J Bras Pneumol Publicaçaäo of Soc Bras Pneumol E Tisilogia 2011; 37: 144-51.

15. Murdaca G, Spanò F, Contatore M, Guastalla A, Puppo F. Potential use of TNF-alpha inhibitors in systemic sclerosis. Immunotherapy 2014; 6: 283-9.

16. Gatta G, Di Grezia G, lacomino A, et al. HRCT in systemic sclerosis: correlation between respiratory functional 
indexes and extension of lung failure. J Biol Regul Homeost Agents 2013; 27: 579-87.

17. Fries JF, Hochberg MC, Medsger TA Jr, Hunder GG, Bombardier C. Criteria for rheumatic disease. Different types and different functions. The American College of Rheumatology Diagnostic and Therapeutic Criteria Committee. Arthritis Rheum 1994; 37: 454-62.

18. LeRoy EC, Black C, Fleischmajer R, et al. Scleroderma (systemic sclerosis): classification, subsets and pathogenesis. J Rheumatol 1988; 15: 202-5.

19. Randone SB, Guiducci S, Cerinic MM. Musculoskeletal involvement in systemic sclerosis. Best Pract Res Clin Rheumatol 2008; 22: 339-50.

20. Miller MR, Hankinson J, Brusasco V, et al. Standardisation of spirometry. Eur Respir J 2005; 26: 319-38.

21. Caramaschi P, Biasi D, Caimmi C, et al. Relationship between body composition and both cardiovascular risk factors and lung function in systemic sclerosis. Clin Rheumatol 2014; 33: 77-82.

22. Rossi A, Fantin F, Di Francesco V, et al. Body composition and pulmonary function in the elderly: a 7 -year longitudinal study. Int J Obes 2005 2008; 32: 1423-30.

23. Pope JE. Musculoskeletal involvement in scleroderma. Rheum Dis Clin North Am 2003; 29: 391-408.

24. Braun NM, Arora NS, Rochester DF. Respiratory muscle and pulmonary function in polymyositis and other proximal myopathies. Thorax 1983; 38: 616-23. 